\title{
Improvement in Bovine Embryo Production In Vitro by Glutathione-Containing Culture Media
}

\author{
GAIA C. LUVONI, ${ }^{1,2}$ LEVENT KESKINTEPE, ${ }^{1}$ AND BENJAMIN G. BRACKETT ${ }^{\boldsymbol{x}}$ \\ ${ }^{1}$ Department of Physiology and Pharmacology, College of Veterinary Medicine, The University of Georgia, Athens, \\ Georgia; ${ }^{2}$ Istituto di Clinical Osterica e Ginecologica Veterinaria, Universita' degli Studi di Milano, Milano, Italy
}

\begin{abstract}
Bovine oocytes were matured, fertilized, and cultured (TCM 199 with serum and co-culture) in vitro (IVMFC) with addition, during different phases of the procedure, of antioxidants: superoxide dismutase (SOD) and reduced glutathione (GSH). The addition of SOD $(1,500$ or $3,000 \mathrm{IU} / \mathrm{ml}$ ) did not improve proportions of oocytes undergoing cleavage or the development of embryos to morula and blastocyst stages. The cleavage rates were significantly lower than in the control group (CTR 57.5\%) when SOD was present during the insemination interval (IVF) or throughout the entire procedure (IVMFC). Thus when the lower concentration was present for IVF and IVMFC, $35.1 \%$ and $36.4 \%$ of inseminated oocytes cleaved $(P<0.01$ compared to CTR $)$ and cleavage results with the higher concentration during IVF and IVMFC were $38.5 \%$ and $29.2 \%(P<0.025$ and $P<0.001$ compared to CTR, respectively). Significant improvements in proportions of oocytes undergoing cleavage $(84.5 \%$ vs. $57.0 \%, P<0.001)$ and morula/blastocyst development $(33.3 \%$ vs. $13.9 \%$, $P<0.005)$ were achieved when GSH $(1 \mathrm{mM})$ was added to the culture medium. In a defined medium for culture (mSOF and BSA) the presence of SOD $(3,000 \mathrm{IU} / \mathrm{ml})$ was ineffective, but in a defined medium supplemented with GSH (1 mM) at day 6 postinsemination (i.e., when $90 \%$ of developing embryos were in 8-16 cell stages), development to the morula and blastocyst stages was supported for $35.5 \%$ of cultured oocytes $(P<0.005$ compared to $19.2 \%$ for CTR). These data suggest that bovine embryos are sensitive to oxidative stress and that medium supplementation with the radical scavenger glutathione can improve embryo development in vitro. (c) 1996 Wiley-Liss, Inc.
\end{abstract}

Key Words: Bovine embryos, Superoxide dismutase, Glutathione, Development, In vitro

\section{INTRODUCTION}

In vitro culture of mammalian embryos has been widely investigated in efforts to overcome the developmental retardation occurring in vitro and to approximate efficiency provided in vivo. One of the major differences between the in vivo and the in vitro environment for the embryo is the oxygen concentration (Bishop, 1956; Mastroianni and Jones, 1965; Maas et al., 1976). Lowering the oxygen concentration in vitro may enhance embryonic development (mouse: Quinn and Harlow, 1978; Pabon et al., 1989; sheep and cow: Tervit et al., 1972; Thompson et al., 1990; goat: Batt et al., 1991). Reactive oxygen species, derived from oxygen metabolism, are apparently involved in the "two-cell block" of mouse embryos (Nasr-Esfahani et al., 1990; Nasr-Esfahani and Johnson, 1991, 1992). Generation of free radicals is an inevitable consequence of oxidative reactions; cellular protective processes have evolved to include "antioxidants" or "free radical scavengers." The latter prevent cellular damage caused by free radical reactions with essential biochemical components by interfering with inactivation of enzymes and alterations of membranes and DNA ( $\mathrm{Yu}$, 1994).

Several studies with mouse embryos (Noda et al., 1989, 1991; Nonogaky et al., 1991; Umaoka et al., 1991, 1992; Chun et al., 1994) indicate that the two-cell block occurring in vitro could be alleviated by protection against oxidative stress mediated via a potent scavenger of oxygen radicals, superoxide dismutase (SOD). Moreover, Legge and Sellens (1991) reported that when reduced glutathione (GSH) was added to a serum-free medium for the culture of mouse embryos, development to the morula or blastocyst stage was promoted, but neither SOD nor catalase had any effect on the embryonic development. In contrast, Payne et al. (1992) observed different effects on development in vitro for onecell mouse embryos of different strains after adding SOD or catalase to the culture medium, and concluded that the developmental block may not be overcome simply by addition of the antioxidant enzymes. Lauria et al. (1994) observed that addition of SOD from oocyte collection to day 8 of culture under $5 \% \mathrm{CO}_{2}$ in air improved the cleavage rate of in vitro-inseminated bovine oocytes without further development.

These conflicting data and the need for studies regarding the effect of antioxidants on in vitro production of bovine embryos prompted our investigation. Putative beneficial effects of SOD and GSH for in vitro production of bovine embryos were assessed. Each oxygen toxicity protecting agent was included in incubation under lowered $(5 \%)$ oxygen concentration during in vitro maturation (IVM), fertilization (IVF), and culture

Received August 9, 1994; accepted August 18, 1995.

Address reprint requests to Dr. Benjamin G. Brackett, Department of Physiology and Pharmacology, College of Veterinary Medicine, The University of Georgia, Athens, Georgia 30602-7389. 
(IVC), and during the entire procedure (IVMFC). To further delineate the period of greatest influence, presumptive zygotes or embryos were cultured in SOD- or GSH-supplemented defined medium.

\section{MATERIALS AND METHODS}

Each experiment was performed at $39^{\circ} \mathrm{C}$ in media under paraffin oil and a humidified atmosphere of 5\% $\mathrm{CO}_{2}, 5 \% \mathrm{O}_{2}$, and $90 \% \mathrm{~N}_{2}$. Superoxide dismutase (CuZn SOD from bovine erythrocytes: S-5395) and reduced glutathione (G-6013) were purchased from Sigma Chemical Co. (St. Louis, MO).

\section{In Vitro Maturation}

Immature bovine cumulus-oocyte complexes (COCs) were aspirated from small $(2-5 \mathrm{~mm})$ antral follicles within 15 min of slaughter, using an 18 gauge needle attached to a $10 \mathrm{ml}$ syringe. Aspirated follicular fluids were pooled in a $50 \mathrm{ml}$ tissue culture flask and maintained between $30^{\circ} \mathrm{C}$ and $33^{\circ} \mathrm{C}$ for $2 \mathrm{hr}$ during transit. Subsequent oocyte handling was performed at $39^{\circ} \mathrm{C}$. The pooled follicular fluid was poured into $15 \mathrm{ml}$ conical tubes, and COCs were allowed to gravitate during a 10-15 min interval. Oocytes were selected as previously described (Younis et al., 1989; Kastrop et al., 1990 ), and then randomly assigned to individual treatment drops (100 $\mu \mathrm{l}, 15-20 \mathrm{COCs} /$ drop) and incubated for $24-25 \mathrm{hr}$.

Undefined conditions (experiments I and II). The IVM medium consisted of TCM 199 with Earle's salts (No. M-5017, Sigma Chemical Co.) supplemented with sodium bicarbonate $(2.6 \mathrm{mg} / \mathrm{ml})$, sodium pyruvate (50 $\mu \mathrm{g} / \mathrm{ml})$, gentamicin sulfate $(50 \mu \mathrm{g} / \mathrm{ml}), 0-\mathrm{LH}(50 \mu \mathrm{g} /$ $\mathrm{ml}$; NIDDK-oLH-26), and proestrous (day 20) cow serum ( $20 \%$ v:v).

Defined conditions (experiments III and IV). The IVM medium consisted of modified TCM 199 (No. M-3769, Sigma Chemical Co.) supplemented as above but with $100 \mu \mathrm{g} \mathrm{o-LH/ml} \mathrm{and} \mathrm{without} \mathrm{serum.}$

\section{In Vitro Fertilization}

Frozen-thawed bull semen was prepared for IVF in a similar manner to the method of Parrish et al. (1986) as modified in our laboratory (Younis et al., 1989). Briefly, in each of six test tubes, $0.1 \mathrm{ml}$ of thawed semen was layered under $1.5 \mathrm{ml}$ HEPES-TALP, and sperm cells were allowed to swim up for $1 \mathrm{hr}$ at $39^{\circ} \mathrm{C}$. The top $1 \mathrm{ml}$ from each tube was then removed and pooled in a $15 \mathrm{ml}$ conical tube, and centrifuged $(350 \times \mathrm{g}, 10 \mathrm{~min})$. After the supernatant was discarded, the sperm pellet was resuspended with $5.0 \mathrm{ml}$ HEPESTALP and recentrifuged as before. The supernatant was again discarded, and the sperm pellet $(100 \mu \mathrm{l})$ was added to $100 \mu \mathrm{l}$ heparin-containing (heparin, sodium salt, Sigma H-7005, $200 \mu \mathrm{g} / \mathrm{ml}$ ) HEPES-TALP in a microcentrifuge tube, for a $15 \mathrm{~min}$ incubation at a final concentration of $100 \mu \mathrm{g}$ heparin/ml. Matured oocytes were washed once in IVF-TALP (Younis and Brackett, 1992) under paraffin oil. Oocytes were transferred to 50 $\mu l$ drops of IVF-TALP (10-15 COCs/drop) and coincubated with approximately $10^{5}$ motile sperm cells per drop (yielding final concentrations of $10^{6}$ sperm and approximately $6 \mu \mathrm{g}$ heparin per $\mathrm{ml}$ ) for $24 \mathrm{hr}$.

\section{In Vitro Culture}

The cumulus cells still surrounding the inseminated oocytes were mechanically removed by gentle aspiration with a glass pipette and oocytes were transferred to each of several $100 \mu \mathrm{l}$ culture drops under oil. In all IVC trials, using undefined and defined conditions, $10 \mathrm{em}$ bryos were cultured in each drop. Medium $(50 \mu \mathrm{l})$ was removed from each culture drop and replaced with $50 \mu \mathrm{l}$ of fresh medium daily.

Undefined conditions (experiments I and II). Drops for IVC contained a cumulus cell monolayer in HEPES-buffered TCM 199 (No. M2520, Sigma Chemical Co.) supplemented with sodium bicarbonate $(2.2$ $\mathrm{mg} / \mathrm{ml})$, sodium pyruvate $(50 \mu \mathrm{g} / \mathrm{ml})$, gentamicin sulfate $(50 \mu \mathrm{g} / \mathrm{ml}$ ), and proestrus (day 20 ) cow serum (10\% v:v).

Cumulus cell cultures were initiated at time of oocyte recovery, and the medium $(50 \mu \mathrm{l})$ was replaced with fresh medium before introducing the oocytes (i.e., presumptive zygotes).

Defined conditions (experiments III and IV). The IVC medium consisted of synthetic oviduct fluid (SOF, Tervit et al., 1972) modified by the addition of MEM nonessential amino acids $(10 \mu \mathrm{l} / \mathrm{ml}$; Sigma Chemical Co.), HEPES ( $25 \mathrm{mM})$, sodium citrate $(0.5 \mathrm{mM})$, and BSA $(8 \mathrm{mg} / \mathrm{ml})$ (Brackett and Keskintepe, 1994). The culture was performed without a somatic cell monolayer.

\section{Design and Analysis}

Four separate experiments, each using a completely randomized design, were performed to evaluate the effect of the addition of SOD or GSH on different phases of the in vitro procedure for obtaining bovine embryos from immature oocytes.

In experiment I the effects of the addition of 1,500 or $3,000 \mathrm{IU} \mathrm{SOD} / \mathrm{ml}$, and in experiment II the effects of the addition of $1 \mathrm{mM}$ GSH to the IVM, IVF, IVC or IVMFC media in undefined conditions, were compared to the control (CTR) group. Effects were reflected by data on cleavage (taken as evidence for fertilization) recorded at $46-48 \mathrm{hr}$ after oocyte insemination and by data on embryonic development to morula and blastocyst stages recorded at 8 days after insemination.

The effects of the additions of $3,000 \mathrm{IU} \mathrm{SOD} / \mathrm{ml}$ (experiment III) and $1 \mathrm{mM}$ GSH (experiment IV) to defined culture medium at different time intervals after insemination (IVC day 2-10; IVC day 2-5; IVC day 6-10) were compared to the control group. Effects were reflected by data on embryos developing to morula and blastocyst stages recorded at 8 days after insemination and by data on embryos reaching the expanded blastocyst stage by 10 days after insemination.

Statistical differences between proportions reflecting various treatments were ascertained by $\chi^{2}$ test. A $P$ 
TABLE 1. Effects of Added Superoxide Dismutase (SOD) for IVM, IVF, IVC, and IVMFC on the Development of In Vitro-Inseminated Bovine Oocytes (Experiment I)*

\begin{tabular}{|c|c|c|c|c|c|}
\hline \multirow{2}{*}{$\begin{array}{l}\text { Treatment } \\
\text { SOD } \\
(\mathrm{IU} / \mathrm{ml})\end{array}$} & \multirow[b]{2}{*}{ Interval } & \multicolumn{4}{|c|}{ No. of oocytes/embryos } \\
\hline & & Inseminated & Cleaved (\%) & $\begin{array}{c}\text { Morulae and } \\
\text { blastocysts }(\%)\end{array}$ & $\begin{array}{c}\text { \% Cleaved reaching } \\
\text { morulae and blastocysts }\end{array}$ \\
\hline 0 (Control) & IVMFC & 73 & $42(57.5)^{\mathrm{a}, \mathrm{A}, \mathrm{C}}$ & $19(26.0)^{d, e, E, F}$ & $45.2^{h, H}$ \\
\hline \multirow[t]{4}{*}{1,500} & IVM & 74 & $40(54.1)^{\mathrm{a}}$ & $27(36.5)^{e}$ & $67.5^{\mathrm{i}}$ \\
\hline & IVF & 74 & $26(35.1)^{b}$ & $12(16.2)^{\mathrm{d}, \mathrm{f}}$ & $46.1^{h}$ \\
\hline & IVC & 65 & $34(52.3)^{\mathrm{a}, \mathrm{c}}$ & $8(12.3)^{\mathrm{f}}$ & $23.5^{\mathrm{j}}$ \\
\hline & IVMFC & 77 & $28(36.4) \mathrm{d}, \mathrm{f}$ & $13(16.9)^{\mathrm{d}, \mathrm{f}}$ & $46.4^{h}$ \\
\hline \multirow[t]{4}{*}{3,000} & IVM & 67 & $35(52.2)^{\mathrm{A}, \mathrm{B}}$ & $17(25.4)^{\mathrm{E}, \mathrm{F}}$ & $48.6^{\mathrm{H}}$ \\
\hline & IVF & 65 & $25(38.5)^{\mathrm{B}, \mathrm{D}}$ & $10(15.4)^{\mathbf{E}, \mathbf{F}}$ & $40.0^{\mathrm{H}}$ \\
\hline & IVC & 73 & $51(69.9)^{\mathrm{C}}$ & $24(32.9)^{\mathrm{F}}$ & $47.0^{\mathrm{H}}$ \\
\hline & IVMFC & 72 & $21(29.2)^{D}$ & $7(9.7)^{\mathrm{G}}$ & $33.3^{\mathrm{H}}$ \\
\hline
\end{tabular}

*Pooled data from 3 replicates.

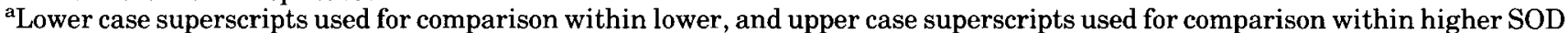
concentration and with untreated control. Different superscripts within treatment concentrations and with control values denote significant differences; also, underlined entries within columns are significantly different $(P<0.05)$.

TABLE 2. Effect of Adding GSH (1 mM) for IVM, IVF, IVC, and IVMFC on the Development of In Vitro-Inseminated Bovine Oocytes (Experiment II)*

\begin{tabular}{lcccc}
\hline & \multicolumn{4}{c}{ No. of oocytes/embryos } \\
\cline { 2 - 5 } Treatment & & \multicolumn{4}{c}{$\begin{array}{c}\text { Morulae and } \\
\text { GSH }(1 \mathrm{mM})\end{array}$} & $\begin{array}{c}\text { \% Cleaved reaching } \\
\text { Inseminated }\end{array}$ & $\begin{array}{c}\text { Cleaved (\%) } \\
\text { morulae and blastocysts }\end{array}$ \\
\hline Control & 79 & $45(57.0)^{\mathrm{a}}$ & $11(13.9)^{\mathrm{c}}$ & $24.4^{\mathrm{e}, \mathrm{f}}$ \\
IVM & 77 & $51(66.2)^{\mathrm{a}}$ & $14(18.2)^{\mathrm{c}}$ & $27.4^{\mathrm{e}, \mathrm{f}}$ \\
IVF & 81 & $49(60.5)^{\mathrm{a}}$ & $9(11.1)^{\mathrm{c}}$ & $18.4^{\mathrm{e}}$ \\
IVC & 84 & $71(84.5)^{\mathrm{b}}$ & $28(33.3)^{\mathrm{d}}$ & $39.4^{\mathrm{f}}$ \\
IVMFC & 68 & $36(52.9)^{\mathrm{a}}$ & $11(16.2)^{\mathrm{c}}$ & $30.5^{\mathrm{e}, \mathrm{f}}$ \\
\hline
\end{tabular}

*Pooled data from 3 replicates

${ }^{a}$ Different superscripts within columns denote significant differences $(P<0.05)$.

value of less than 0.05 was considered statistically significant.

\section{RESULTS}

Experiment I: Effect of Superoxide Dismutase (SOD) on IVM, IVF, IVC, and IVMFC in Undefined Conditions

Results of experiment I revealed no significant increases in the proportions of oocytes that cleaved when $\operatorname{SOD}(1,500$ or $3,000 \mathrm{IU} / \mathrm{ml})$ was added to media for IVM or IVC (Table 1). However, inclusion of 1,500 IU $\mathrm{SOD} / \mathrm{ml}$ during IVM apparently improved quality of oocytes since $67.5 \%$ of resulting 2-4-cell embryos reached morulae and blastocysts documenting significant improvement $(P<0.05)$ in developmental potential after this treatment. Cleavage rates were significantly lower than in the control group (57.5\%) when SOD (either 1,500 or $3,000 \mathrm{IU} / \mathrm{ml}$ ) was present during the insemination interval (IVF) or throughout (IVMFC). Thus, when the lower concentrations was present for IVF and IVMFC, $35.1 \%$ and $36.4 \%$ of inseminated oocytes cleaved $(P<0.01$ compared to CTR). Cleavage results with the higher concentration during IVF and IVMFC were $38.5 \%$ and $29.2 \%(P<0.025$ and $P<0.001$ when compared to CTR, respectively). The development of embryos to morula and blastocyst stages was not improved by the addition of 1,500 or
$3,000 \mathrm{IU} \mathrm{SOD} / \mathrm{ml}$ to media for IVF, IVC, or IVMFC. A beneficial effect was seen when both cleavage $(P<0.05)$ and advanced development $(P<0.005$; morula and blastocyst stages) resulting from the higher SOD concentration during IVC were compared with those from the lower concentration (underlined in Table 1); however, the highest values for IVC, i.e., those resulting from addition of 3,000 IU SOD, were not significantly improved over untreated control cleavage and uterine stage embryonic development.

\section{Experiment II: Effect of GSH on IVM, IVF, IVC, and IVMFC in Undefined Conditions}

As shown in Table 2, when compared to control values significantly higher proportions of oocytes cleaved $(84.5 \%$ vs. $57.0 \%, P<0.001)$ and reached the morula and blastocyst stages $(33.3 \%$ vs. $13.9 \%, P<0.005)$ when GSH ( $1 \mathrm{mM}$ ) was included in culture medium.

\section{Experiment III: Effect of SOD on IVC (d2-10, d2-5, d6-10) in Defined Conditions}

The development of inseminated oocytes to the morula and blastocyst, and to expanded blastocyst stages was not improved when SOD was added to the defined conditions of culture throughout or for different time intervals (Table 3). Although the highest values did not significantly exceed those of the untreated con- 
TABLE 3. Effect of the Addition of 3,000 IU/ml of SOD for In Vitro Culture on the Development of In Vitro-Inseminated Bovine Oocytes (Experiment III)*

\begin{tabular}{|c|c|c|c|c|}
\hline \multirow{2}{*}{$\begin{array}{l}\text { Treatment } \\
\text { SOD } \\
(\mathrm{IU} / \mathrm{ml})\end{array}$} & \multirow[b]{2}{*}{ Interval } & \multicolumn{3}{|c|}{ No. of oocytes/embryos } \\
\hline & & Inseminated & $\begin{array}{c}\text { Morulae and } \\
\text { blastocysts }(\%)\end{array}$ & $\begin{array}{c}\text { Expanded } \\
\text { blastocysts }(\%) \\
\end{array}$ \\
\hline $\begin{array}{l}\mathbf{0} \text { (Control) } \\
\mathbf{3 , 0 0 0}\end{array}$ & $\begin{array}{l}\text { IVMFC } \\
\text { IVC }(\mathrm{d} 2-10) \\
\text { IVC }(\mathrm{d} 2-5) \\
\text { IVC }(\mathrm{d} 6-10)\end{array}$ & $\begin{array}{l}103 \\
130 \\
126 \\
113\end{array}$ & $\begin{array}{l}18(17.5)^{a} \\
19(14.6)^{a, b} \\
11(8.7)^{b} \\
19(16.8)^{a, b}\end{array}$ & $\begin{array}{l}6(5.8)^{\mathrm{c}, \mathrm{d}} \\
9(6.9)^{\mathrm{c}, \mathrm{d}} \\
3(2.4)^{\mathrm{c}} \\
9(8.0)^{\mathrm{d}}\end{array}$ \\
\hline
\end{tabular}

*Pooled data from 3 replicates.

a Different superscripts within columns denote significant differences $(P<0.05)$.

TABLE 4. Effect of Adding GSH (1 mM) During Culture on the Development of In Vitro-Inseminated Bovine Oocytes (Experiment IV)*

\begin{tabular}{lccc}
\hline & \multicolumn{3}{c}{ No. of oocytes/embryos } \\
\cline { 2 - 4 } Treatment & Inseminated & $\begin{array}{c}\text { Morulae and } \\
\text { blastocysts }(\%)\end{array}$ & $\begin{array}{c}\text { Expanded } \\
\text { blastocysts }(\%)\end{array}$ \\
\hline Control & 125 & $24(19.2)^{\mathrm{a}}$ & $6(4.8)^{\mathbf{c}}$ \\
IVC (d2-10) & 130 & $17(13.1)^{\mathrm{a}}$ & $0(0.0)^{\mathrm{d}}$ \\
IVC (d2-5) & 124 & $21(16.9)^{\mathrm{a}}$ & $0(0.0)^{\mathrm{d}}$ \\
IVC (d6-10) & 110 & $39(35.5)^{\mathrm{b}}$ & $8(7.3)^{\mathrm{c}}$ \\
\hline
\end{tabular}

*Pooled data from three replicates.

${ }^{a}$ Different superscripts within columns denote significant differences $(P<0.05)$.

trol, the presence of SOD during the last half of the IVC interval (i.e., d6-10) enabled significantly $(P<0.025)$ better advanced embryonic development than when SOD was present during the first part of IVC (Table 3).

\section{Experiment IV: Effect of GSH on IVC (d2-10, d2-5, d6-10) in Defined Conditions}

Data shown in Table 4 delineates the interval during which GSH exerted a beneficial effect. By day 6 postinsemination $90 \%$ of the fertilized (cleaved) oocytes (in conditions for Table 4) reached 8-16-cell stage development. A significant improvement in the proportions of inseminated oocytes that reached morula and blastocyst stages was observed after adding GSH for days $6-10$ of IVC in defined conditions $(35.5 \%$ vs. $19.2 \%$, $P<0.005$ ). The presence of GSH from day 2 to 5 of culture (i.e., $\mathrm{d} 2-10$ and $\mathrm{d} 2-5$ ) significantly depressed to zero the development to the expanded blastocyst stage.

\section{DISCUSSION}

Active oxygen-derived intermediates (superoxide radicals $\mathrm{O}_{2}^{-}$, hydroxyl radicals $\cdot \mathrm{OH}$, and hydrogen peroxide $\mathrm{H}_{2} \mathrm{O}_{2}$ ) react with proteins, lipids, and DNA, resulting in inactivation of enzymes, membrane lipid peroxidation, and DNA alterations. Cells have evolved their own protective system against the products of oxygen metabolism. Eucaryotic cells contain $\mathrm{Cu} / \mathrm{Zn}$ SOD in the cytosolic compartment and GSH in high intracellular concentrations in a variety of tissues (Yu, 1994).

A potent scavenger of superoxide radicals, SOD catalyzes their dismutation as follows: $\mathrm{O}_{2}{ }^{-}+\mathrm{O}_{2}{ }^{-}$
$+2 \mathrm{H}^{+} \quad \mathrm{H}_{2} \mathrm{O}_{2}+\mathrm{O}_{2}$ (McCord and Fridovich, 1969). The presence of $\mathrm{Cu} / \mathrm{Zn}$ SOD has been detected in the nucleus and cytoplasm of the epithelial cells of human fallopian tube (Narimoto et al., 1991), in rabbit oviductal fluid (Noda et al., 1991), and in follicular, oviductal, and uterine fluids in the mouse (Chun et al., 1994), suggesting a protective role of this enzyme in combating oxidative stress of oocytes and developing embryos.

Reduced GSH, a tripeptide, plays an important role as a cellular antioxidant interacting with superoxide and hydroxyl radicals. As the substrate in the reduction of $\mathrm{H}_{2} \mathrm{O}_{2}$ catalyzed by glutathione peroxidase, GSH detoxifies intracellular peroxides. It is synthesized intracellularly and transported across cell membranes (Meister, 1983). An extracellular role of GSH in the prevention of lipid peroxidation of cellular membranes by extracellular active oxygen species has also been reported (Thomas et al., 1988; Avissar et al., 1989).

Although a beneficial effect of low oxygen concentration on embryonic development in vitro has been widely demonstrated (Quinn and Harlow, 1978; Pabon et al., 1989; Tervit et al., 1972; Thompson et al., 1990; Batt et al., 1991), oocytes and embryos are inevitably more exposed to oxygen and other insults in vitro than in vivo because of the necessary manipulations with transient exposure to atmospheric oxygen and visible light. Illumination is known to enhance the generation of oxygen radicals (Halliwell and Gutteridge, 1989), and effects of visible light in the production of oxygen radicals in the culture of hamster and mouse embryos have been reported (Goto et al., 1993; Nakayama et al., 1994). 


\section{Effect of SOD and GSH During IVM}

In spite of the above rationale, addition of exogenous $\mathrm{Cu} / \mathrm{Zn}$ SOD or GSH to the maturation medium did not increase proportions of oocytes that cleaved and developed further in vitro (Tables 1 and 2). However, the percentage of cleaved oocytes reaching morula and blastocyst stages was higher $(P<0.05)$, suggesting improved quality of oocytes matured in vitro with 1,500 IU SOD per ml (Table 1). Developmental competence of oocytes is strictly dependent on their (nuclear, cytoplasmic, and membrane) maturation. This SOD treatment was apparently effective in protecting oocytes from superoxide radicals during maturation.

The ineffective addition of GSH might be explained by the fact that the cumulus cells surrounding the oocytes are GSH rich, as already shown in the hamster (Zuelke and Perreault, 1994). This should sufficiently protect oocytes from free radical damage, as previously reported in the mouse (Legge, 1989). In the latter work, hydrogen peroxide production was detected in oocytes and with increased levels in zygotes, but not in the cumulus oophorus. Moreover, experiments I and II were carried out in commercially obtained TCM 199 already containing a very small amount of GSH $(0.05$ $\mathrm{mg} / \mathrm{l})$ and its precursor cysteine $(0.11 \mathrm{mg} / \mathrm{ml})$, to which serum with many unknown components was added. The presence of GSH, even in the control group, could be sufficient to protect oocytes from oxidative stress and the cysteine could support a good level of GSH synthesis during in vitro maturation to decrease chances of finding expected differences between untreated and treated groups.

\section{Effect of SOD and GSH During the Insemination Interval (IVF)}

Reactive oxygen species are deleterious to sperm cells, which are particularly sensitive to lipid peroxidation (Lardy and Phillips, 1941; McLeod, 1943; Holland and Storey, 1981). Vandermark et al. (1949) postulated that part of the deleterious effect of high oxygen tension on bull sperm motility is caused by increased $\mathrm{H}_{2} \mathrm{O}_{2}$ production, and that is prevented by the addition of catalase, in which bovine sperm is particularly deficient (Mann, 1964).

Additions of SOD and/or GSH for protection of spermatozoa of different species have been reported (SOD: human: Alvarez et al., 1987; Kobayashi et al., 1991; rabbit: Holland et al., 1982; bull: Mennella and Jones, 1980; Magnes and Li, 1980; GSH: mouse: Alvarez and Storey, 1984; dog, ram, and goat: $\mathrm{Li}, 1975$ ). A physiological role of reactive oxygen species in mediating spermzona interaction by the induction of lipid peroxidation has been suggested (Aitken et al., 1989), and positive effects of superoxide radicals in the hyperactivation and capacitation in vitro of human (de Lamirande and Gagnon, 1993) and hamster (Bize et al., 1991) sperm cells have been noted. Diminished generation of superoxide during the interaction of human gametes has been demonstrated and attributed to the release of SOD during this phase (Miesel et al., 1993). Our results (Table 1) showed a significant depressing effect of SOD during the insemination interval in contrast with findings of no effects on mouse fertilization reported by Nonogaky et al. (1992). An explanation for the negative effect of SOD in our experiment could be compromise of a positive role of active oxygen species during fertilization. An alternative explanation might include toxicity of hydrogen peroxide, rather than superoxide radical, as reported for human sperm movement and for the capacity of human sperm cells to acrosome react and fuse with the egg membrane (Aitken et al., 1993). Thus, Aitken et al. (1993) concluded that the presence of SOD might be deleterious since the product of dismutation $\left(\mathrm{H}_{2} \mathrm{O}_{2}\right)$ is more harmful than $\mathrm{O}_{2}{ }^{-} \cdot$. Toxicity affecting the oocyte, or sperm quality as reflected by decreased embryonic development represent possibilities since SOD treatment of sperm prior to insemination did not decrease fertilization rates (unpublished data).

\section{Effect of SOD and GSH During IVC}

Protection of embryos from oxidative stress may be a prerequisite for development in vitro because of extreme sensitivity to superoxide anions. Addition of SOD to the culture medium has facilitated development of mouse embryos through the two-cell block and culture of rabbit embryos under either high (Noda et al., 1991; Chun et al., 1994; Li et al., 1993) or low oxygen conditions (Umaoka et al., 1991, 1992) without somatic cell monolayer co-culture support. Nonogaky et al. (1991) demonstrated that SOD is most effective when applied 7-30 $\mathrm{hr}$ after insemination in the mouse, approximately the time of the developmental block. The positive effect of SOD $(\mathrm{Cu} / \mathrm{Zn}$ SOD from bovine erythrocytes or recombinant human) has been obtained with concentrations around $1,500 \mathrm{IU} / \mathrm{ml}$ or higher. In our system of bovine in vitro-derived embryos cultured under low oxygen tension and with coculture of cumulus cells or in defined medium (Tables 1,3 ), the addition of SOD $(1,500-3,000 \mathrm{IU} / \mathrm{ml})$ did not improve the development to morula and blastocyst stages. This might be due to the undefined conditions including the monolayer that lowers the oxygen tension in the immediate vicinity of the embryos as proposed by Bavister (1988). In the defined conditions the antioxidant role of BSA suggested by Natsuyama et al. (1993) might have the same effect. Furthermore, hydrogen peroxide is highly involved in blocking development. The period of in vitro development at which this block occurs in the mouse embryo (the mid-two-cell stage to the early fourcell stage) is associated with a rise in reactive oxygen species such as $\mathrm{H}_{2} \mathrm{O}_{2}$ (Nasr-Esfahani et al., 1990; Noda et al., 1991). The ineffective action of SOD and the significantly improved development in the culture medium for bovine embryos supplemented with GSH (Table 2) are in agreement with findings for mouse embryos cultured under high oxygen concentration in serum-free medium (Legge and Sellens, 1991; Gardiner 
and Reed, 1994). GSH showed a beneficial effect on development, and the greatest influence was with addition on day 6 postinsemination in the present work. One of the effects of GSH, as previously mentioned, is the reduction of $\mathrm{H}_{2} \mathrm{O}_{2}$ acting as a substrate of GSH peroxidase; the importance of $\mathrm{H}_{2} \mathrm{O}_{2}$ in the block of development was described above. In vitro development is usually retarded; thus, day 6 postinsemination, corresponding to the time that embryos progress from 8-16 cells to the morula stage, is a phase in which they could be more sensitive to the oxidative stress. Our finding of a protective role for extracellular GSH in embryo culture is compatible with the findings of Takahashi et al. (1993), who added low-molecular-weight thiol compounds to improve bovine blastocyst development in the presence of serum, and the work of Gardiner and Reed (1994), who reported lowered intracellular GSH content with mouse embryo development up to the blastocyst stage.

Proportions of oocytes developing to morula and blastocyst stages were not increased by the presence of SOD in maturation and culture medium, and SOD was deleterious when present during the insemination interval. Interestingly, cleaved oocytes after IVM with an appropriate concentration of SOD demonstrated greater viability in vitro. The addition of GSH for culture significantly improved the development of bovine embryos. The efficacy of exogenous GSH in enhancing development emphasizes a possible extracellular role since intracellular concentrations of GSH are generally adequate and GSH is not readily transported into cells (Meister, 1983). Several factors are involved in the retardation of in vitro development, and one most likely is oxidative stress. Supplementation of culture media for bovine embryos with antioxidants seems worthy of consideration.

\section{ACKNOWLEDGMENTS}

We gratefully acknowledge the support of UGA VMES 94-208, and Transgenic Products, Inc., Atlanta, GA; Atlantic Breeders Cooperative, Lancaster, PA; National Hormone and Pituitary Program, NIDDK, NICHD, and USDA; National Research Council Italy, Project RAISA s.p. 3, Paper No. 1705; and Shapiro Packing Co., Augusta, GA.

\section{REFERENCES}

Aitken RJ, Clarkson JS, Fishel S (1989): Generation of reactive oxygen species, lipid peroxidation, and human sperm function. Biol Reprod 40:183-197.

Aitken RJ, Buckingham D, Harkiss D (1993): Use of a xanthine oxidase free radical generating system to investigate the cytotoxic effects of reactive oxygen species on human spermatozoa. J Reprod Fertil 97:441-450.

Alvarez JG, Storey BT (1984): Lipid peroxidation and the reactions of superoxide and hydrogen peroxide in mouse spermatozoa. Biol Reprod 30:833-841.

Alvarez JG, Touchstone JC, Blasco L, Storey BT (1987): Spontaneous lipid peroxidation and production of hydrogen peroxide and superoxide in human spermatozoa. J Androl 8:338-348.

Avissar N, Whitin JC, Allen PZ, Wagner DD, Liegey P, Cohen HJ (1989): Plasma selenium-dependent glutathione peroxidase: Cell origin and secretion. J Biol Chem 264:15850-15855.
Batt PA, Gardner DK, Cameron AWN (1991): Oxygen concentration and protein source affect the development of preimplantation goat embryos in vitro. Reprod Fertil Dev 3:601-607.

Bavister BD (1988): Role of oviduct secretions in embryonic growth in vivo or in vitro. Theriogenology 29:143-154.

Bishop DW (1956): Oxygen concentration in the rabbit genital tract. In DW Bishop (ed): "Proceedings of the Third International Congress of Animal Reproduction, Physiology." London: Brown, Knight and Truscott Ltd., pp 53-58.

Bize I, Santander G, Cabello P, Driscoll D, Sharpe C (1991): Hydrogen peroxide is involved in hamster sperm capacitation in vitro. Biol Reprod 44:398-403.

Brackett BG, Keskintepe L (1994): Improved culture conditions for in vitro production of bovine blastocysts. J Reprod Fertil Abstr Ser 13:13-14.

Chun YS, Kim JH, Lee HT, Chung KS (1994): Effect of superoxide dismutase on the development of preimplantation mouse embryos. Theriogenology 41:511-520.

de Lamirande E, Gagnon C (1993): Human sperm hyperactivation and capacitation as parts of an oxidative process. Free Radic Biol Med 14:157-166.

Gardiner CS, Reed DJ (1994): Status of glutathione during oxidantinduced oxidative stress in the preimplantation mouse embryo. Biol Reprod 51:1307-1314.

Goto Y, Noda Y, Mori T, Nakano M (1993): Increased generation of reactive oxygen species in embryos cultured in vitro. Free Radic Biol Med 15:69-75.

Halliwell B, Gutteridge JMC (1989): The chemistry of oxygen radicals and other oxygen-derived species. In B Halliwell, JMC Gutteridge (eds): "Free Radicals in Biology and Medicine." Oxford: Oxford University Press, pp 22-85.

Holland MK, Storey BT (1981): Oxygen metabolism of mammalian spermatozoa. Generation of hydrogen peroxide by rabbit epididymal spermatozoa. Biochem J 198:273-280.

Holland MK, Alvarez JG, Storey BT (1982): Production of superoxide and activity of superoxide dismutase in rabbit epididymal spermatozoa. Biol Reprod 27:1109-1118.

Kastrop PMM, Bevers MM, Destree OHJ, Kruip TAM (1990): Analysis of protein synthesis in morphologically classified bovine follicular oocytes before and after maturation in vitro. Mol Reprod Dev 26:222-226.

Kobayashi T, Miyazaki T, Natori M, Nozawa S (1991): Protective role of superoxide dismutase in human sperm motility: Superoxide dismutase activity and lipid peroxide in human seminal plasma and spermatozoa. Hum Reprod 6:987-991.

Lardy HA, Phillips PH (1941): The effect of certain inhibitors and activators on sperm metabolism. J Biol Chem 138:195-202.

Lauria A, Luvoni GC, Parravicini E, Gandolfi F (1994): Effect of superoxide dismutase (SOD) on early stages of bovine embryogenesis in vitro. Theriogenology 41:234.

Legge M (1989): Determinants in preimplantation mouse development. PhD Thesis, University of Essex.

Legge M, Sellens MH (1991): Free radical scavengers ameliorate the 2-cell block in mouse embryo culture. Hum Reprod 6:867-871.

Li J, Foote RH, Simkin M (1993): Development of rabbit zygotes cultured in protein-free medium with catalase, taurine, or superoxide dismutase. Biol Reprod 48:33-37.

Li T-K (1975): The glutathione and thiol content of mammalian spermatozoa and seminal plasma. Biol Reprod 12:641-646.

Mass DHA, Storey BT, Mastroianni L Jr (1976): Oxygen tension in the oviduct of the rhesus monkey (Macaca mulatta). Fertil Steril 27: $1312-1317$.

Magnes LJ, Li T-K (1980): Isolation and properties of superoxide dismutase from bovine spermatozoa. Biol Reprod 22:965-969.

Mann T (1964): Catalase. In "The Biochemistry of Semen and of the Male Reproductive Tract." London: Methuen and Co., pp 130-131.

Mastroianni L Jr, Jones, R (1965): Oxygen tension in the rabbit fallopian tube. J Reprod Fertil 9:99-102.

McCord JM, Fridovich I (1969): Superoxide dismutase. An enzymic function for erythrocuprein (hemocuprein). J Biol Chem 244:60496055.

McLeod $J$ (1943): The role of oxygen in the metabolism and motility of human spermatozoa. Am J Physiol 138:512-518. 
Meister A (1983): Selective modifications of glutathione metabolism. Science 220:472-477.

Mennella MRF, Jones R (1980): Properties of spermatozoal superoxide dismutase and lack of involvement of superoxides in metal-ion-catalyzed lipid-peroxidation reactions in semen. Biochem J 191:289297.

Miesel R, Drzejczak PJE, Kurpisz M (1993): Oxidative stress during the interaction of gametes. Biol Reprod 49:918-923.

Nakayama T, Noda Y, Goto Y, Mori T (1994): Effects of visible light and other environmental factors on the production of oxygen radicals by hamster embryos. Theriogenology 41:499-510.

Narimoto K, Noda Y, Shiotani M, Natsuyama S, Mori T, Fujimoto K, Ogawa K, Kim YC (1991): Role of superoxide dismutase in the fallopian tube function: Immunohistochemical assessment of superoxide dismutase in the fallopian tube. Acta Histochem Cytochem 24:85-91.

Nasr-Esfahani MH, Johnson MH (1991): The origin of reactive oxygen species in mouse embryos cultured in vitro. Development 113:551560.

Nasr-Esfahani MH, Johnson MH (1992): Quantitative analysis of cellular glutathione in early preimplantation mouse embryos developing in vivo and in vitro. Hum Reprod 7:1281-1290.

Nasr-Esfahani MH, Aitken JR, Johnson MH (1990): Hydrogen peroxide levels in mouse oocytes and early cleavage stage embryos developed in vitro or in vivo. Development 109:501-507.

Natsuyama S, Noda Y, Narimoto K, Mori T (1993): Role of protein supplements in the culture of mouse embryos. Theriogenology 40 : $149-157$.

Noda Y, Matsumoto H, Mori T (1989): Superoxide dismutase overcomes 2-cell block in mouse embryos. Acta Obstet Gynecol Jpn 41: 751-752.

Noda Y, Matsumoto H, Umaoka Y, Tatsumi K, Kishi J, Mori T (1991): Involvement of superoxide radicals in the mouse two-cell block. Mol Reprod Dev 28:356-360.

Nonogaki T, Noda Y, Narimoto K, Umaoka Y, Mori T(1992): Effects of superoxide dismutase on mouse in vitro fertilization and embryo culture system. J Assist Reprod Genet 9:274-280.

Nonogaky T, Noda Y, Narimoto K, Umaoka Y, Mori T (1991): Protection from oxidative stress by thioredoxin and superoxide dismutase of mouse embryos fertilized in vitro. Hum Reprod 6:1305-1310.

Pabon JE Jr, Findley WE, Gibbons WE (1989): The toxic effect of short exposures to the atmospheric oxygen concentration on early mouse embryonic development. Fertil Steril 51:896-900.
Parrish JJ, Susko-Parrish JL, Leibfried-Rutledge ML, Crister ES, Eyestone WH, First NL (1986): Bovine in vitro fertilization with frozen-thawed semen. Theriogenology 25:591-600.

Payne SR, Munday R, Thompson JG (1992): Addition of superoxide dismutase and catalase does not necessarily overcome developmental retardation of one-cell mouse embryos during in vitro culture. Reprod Fertil Dev 4:167-174.

Quinn P, Harlow GM (1978): The effect of oxygen on the development of preimplantation mouse embryos in vitro. J Exp Zool 206:73-80.

Takahashi M, Nagai T, Hamano S, Kuwayama M, Okamura N, Okano A (1993): Effect of thiol compounds on in vitro development and intracellular glutathione content of bovine embryos. Biol Reprod 49:228-232.

Tervit HR, Whittingham DG, Rowson LEA (1972): Successful culture in vitro of sheep and cattle ova. $J$ Reprod Fertil 30:493-497.

Thomas EL, Learn DB, Jefferson MM, Weatherred W (1988): Superoxide-dependent oxidation of extracellular reducing agents by isolated neutrophils. J Biol Chem 263:2178-2186.

Thompson JGE, Simpson AC, Pugh PA, Donnelly PE, Tervit HR (1990): Effect of oxygen concentration on in vitro development of preimplantation sheep and cattle embryos. J Reprod Fertil 89:573578.

Umaoka Y, Noda Y, Narimoto K, Mori T (1991): Developmental potentiality of embryos cultured under low oxygen tension with superoxide dismutase. J In Vitro Fert Embryo Transf 8:245-249.

Umaoka Y, Noda Y, Narimoto K, Mori T (1992): Effects of oxygen toxicity on early development of mouse embryos. Mol Reprod Dev 31:28-33.

Vandemark NL, Salisbury GW, Bratton RW (1949): Oxygen damage to bull spermatozoa and its prevention by catalase. J Dairy Sci 32:353-360.

Younis AI, Brackett BG (1992): Thyroid stimulating hormone enhancement of bovine oocyte maturation in vitro. Mol Reprod Dev 31:144-151.

Younis AI, Brackett BG, Fayrer-Hosken RA (1989): Influence of serum and hormones on bovine oocyte maturation and fertilization in vitro. Gamete Res 23:189-201.

Yu BP (1994): Cellular defenses against damage from reactive oxygen species. Physiol Rev 74:139-162.

Zuelke KA, Perreault SD (1994): Hamster oocyte and cumulus cell glutathione concentrations increase rapidly during in vivo meiotic maturation. Biol Reprod 50:144. 